\title{
Collaborative Study of an Indirect Enzymatic Method for the Simultaneous Analysis of 3-MCPD, 2-MCPD, and Glycidyl Esters in Edible Oils
}

Kazuo Koyama $^{1 *}$, Kinuko Miyazaki ${ }^{1}$, Kousuke Abe ${ }^{2}$, Yoshitsugu Egawa ${ }^{3}$, Hirotsugu Kido ${ }^{4}$, Tadashi Kitta ${ }^{5}$, Takashi Miyashita ${ }^{6}$, Toru Nezu ${ }^{7}$, Hidenori Nohara ${ }^{8}$, Takashi Sano ${ }^{9}$, Yukinari Takahashi ${ }^{10}$, Hideji Taniguchi ${ }^{11}$, Hiroshi Yada ${ }^{12}$, Kumiko Yamazaki ${ }^{13}$ and Yomi Watanabe ${ }^{14}$

\footnotetext{
${ }^{1}$ Central Research \& Development Institute, House Foods Group Inc. (1-4, Takanodai, Yotsukaido, Chiba 284-0033, JAPAN)

${ }^{2}$ Analysis \& Assessment, Central Research Laboratory, The Nisshin OilliO Group, Ltd.. (1, Shinmei-cho, Yokosuka 239-0832, JAPAN)

${ }^{3}$ Analytical Center for Food Safety, Quality Assurance Department, Fuji Oil Co., Ltd. (1, Sumiyoshi-cho, Izumisano, Osaka 598-8540, JAPAN)

${ }^{4}$ Japan Association for Inspection and Investigation of Foods Including Fats and Oils (3-27-8, Nihonbashi-hamacho, Chuo-ku, Tokyo 103-0007, JAPAN)

${ }^{5}$ Japan Frozen Foods Inspection Corp. (2-13-45, Fukuura, Kanazawa-ku, Yokohama 236-0004, JAPAN)

${ }^{6}$ Quality Assurance Div., Kewpie Corp. (2-5-7, Senkawa-cho,Chohu, Tokyo 182-0002, JAPAN)

${ }^{7}$ Food Development Laboratory, ADEKA Corp. (7-2-34, Higashiogu, Arakawa-ku, Tokyo 116-8553, JAPAN)

${ }^{8}$ Health Care Food Research Laboratories, Kao Corp. (2-1-3, Bunka, Sumida-ku, Tokyo 131-8501, JAPAN)

${ }^{9}$ Fundamental Research Laboratory, J-Oil Mills Inc. (7-41, Dikoku-cho, Tsurumi-ku, Yokohama 230-0053, JAPAN)

${ }^{10}$ Analytical and Technological Solution Service, House Food Analytical Laboratory Inc. (1-4, Takanodai, Yotsukaido, Chiba 284-0033, JAPAN)

${ }^{11}$ General Testing Research Institute, Japan Oilstuff Inspectors Corp. (1-2-15, Mikagetsuka-machi, Higashinada-ku, Kobe 658-0044, JAPAN)

${ }^{12}$ Food Research Institute, National Agriculture and Food Research Organization (NARO) (2-1-12, Kannon-dai, Tsukuba, Ibaraki 305-8642, JAPAN)

${ }^{13}$ Japan Food Research Laboratories, Saito Laboratory (7-4-41, Saitoasagi, Ibaraki, Osaka 567-0085, JAPAN)

${ }^{14}$ Osaka Municipal Technical Research Institute (1-6-50, Morinomiya, Joto-ku, Osaka 536-8553, JAPAN)
}

\begin{abstract}
A collaborative study was conducted to evaluate an indirect enzymatic method for the analysis of fatty acid esters of 3-monochloro-1,2-propanediol (3-MCPD), 2-monochloro-1,3-propanediol (2-MCPD), and glycidol (Gly) in edible oils and fats. The method is characterized by the use of Candida rugosa lipase, which hydrolyzes the esters at room temperature in $30 \mathrm{~min}$. Hydrolysis and bromination steps convert esters of 3-MCPD, 2-MCPD, and glycidol to free 3-MCPD, 2-MCPD, and 3-monobromo-1,2-propanediol, respectively, which are then derivatized with phenylboronic acid, and analyzed by gas chromatographymass spectrometry. In a collaborative study involving 13 laboratories, liquid palm, solid palm, rapeseed, and rice bran oils spiked with $0.5-4.4 \mathrm{mg} / \mathrm{kg}$ of esters of 3-MCPD, 2-MCPD, and Gly were analyzed in duplicate. The repeatability $\left(R S D_{r}\right)$ were $<5 \%$ for five liquid oil samples and $8 \%$ for a solid oil sample. The reproducibility $\left(R S D_{R}\right)$ ranged from $5 \%$ to $18 \%$ for all oil samples. These $R S D_{R}$ values were considered satisfactory because the Horwitz ratios were $\leq 1.3 \%$ for all three analytes in all oil samples. This method is applicable to the quantification of 3-MCPD, 2-MCPD, and Gly esters in edible oils.
\end{abstract}

Key words: collaborative study, indirect method, lipase, MCPD, glycidol

\section{INTRODUCTION}

Fatty acid esters of 3-monochloro-1,2-propanediol (3-MCPD) and glycidol (Gly) are known as contaminants in foods and edible oils. In 1978, free chlorinated propanols, especially 3-MCPD, were detected in acid-hydrolyzed veg- etable protein (acid-HVP) and in soy sauce ${ }^{1)}$. Codex established the maximum level of 3-MCPD in liquid seasonings containing acid-HVP based on an international risk evaluation $^{2}$. In the 1980s, 3-MCPD fatty acid esters (3-MCPD-Es) were found in trace amounts in heat-processed foods ${ }^{3,4)}$.

\footnotetext{
*Correspondence to: Kazuo Koyama, Central Research \& Development Institute, House Foods Group Inc., 1-4, Takanodai, Yotsukaido, Chiba 284-0033, JAPAN

E-mail: k-koyama@ @ousefoods.co.jp

Accepted April 1, 2016 (received for review January 30, 2015)

Journal of Oleo Science ISSN 1345-8957 print / ISSN 1347-3352 online

http://www.jstage.jst.go.jp/browse/jos/ http://mc.manusriptcentral.com/jjocs
} 
K. Koyama, K. Miyazaki and K. Abe et al.

The reports of Weißhaar on the presence of 3-MCPD-Es $(2008)^{5)}$ and glycidol fatty acid esters (Gly-Es) $(2009)^{6,7)}$ in edible oils raised much concern in Europe. Gly-Es were also found in diacylglycerol (DAG)-enriched oils marketed in $\mathrm{Japan}^{8)}$, which attracted public attention.

It is possible that 3-MCPD-Es and Gly-Es in foods and oils are hydrolyzed in vivo to the free-form carcinogens 3-MCPD and Gly. The Japanese Food Safety Commission reported that the toxicity of Gly-Es in DAG-enriched oil was unconfirmed and denied that they showed carcinogenesis promoting activity ${ }^{9)}$. However, the commission did not deny the possibility that Gly-Es might be a genotoxic carcinogen, recommending that Gly-Es levels should be kept as low as possible. The commission also suggested that 3-MCPD-Es would not be genotoxic in vivo. International organizations, such as FAO/WHO Joint Expert Committee on Food Additives (JECFA) and European Food Safety $\mathrm{Au}-$ thority (EFSA), have conducted monitoring surveys and toxicity studies of 3-MCPD-Es and Gly-Es. From 2007 to 2009, German Bundesinstitut für Risikobewertung (BfR) conducted a risk assessment under the assumption that the human body absorbed all Gly resulting from the complete hydrolysis of Gly-Es consumed at concentrations found in foods determined using non-validated methods.

In recent years, the concentrations of 3-MCPD-Es and Gly-Es in edible oils and foods have been surveyed in Japan $^{10)}$ and other countries ${ }^{11)}$. The results of these surveys require continual updating using more precise validated methods. Food manufacturers are voluntarily maintaining or lowering the amounts of 3-MCPD-Es and Gly-Es in their products, and using analysis to monitor their achievements.

Direct and indirect methods have been developed for the analysis of 3-MCPD-Es, 2-monochloro-1,3-propanediol fatty acid esters (2-MCPD-Es), and Gly-Es in edible oils ${ }^{12)}$. In the direct methods, the sample is purified by solid-phase extraction and then individual esters are analyzed by liquid chromatography-mass spectrometry (LC-MS) . A direct analytical method for Gly-Es, reported by Shiro et al., was validated by a joint study by Japan Oil Chemists' Society (JOCS) and American Oil Chemists' Society(AOCS), and was registered as the JOCS Standard Method for the Analysis of Fats, Oils, and Related Materials 2.4.13-2013 ${ }^{13,14}$. Two direct methods for the analysis of 3-MCPD-Es have been reported by Yamazaki et $a l .{ }^{15)}$ and Hori et $a l .{ }^{16,17)}$. As 3 -MCPD can form mono- and diesters with various fatty acids, the direct methods required numerous standard materials and various procedures for sample purification. These direct methods are suitable for the toxicological assessment of individual compounds and elucidation of their formation mechanisms.

In the indirect methods, the esters are hydrolyzed and the resulting glycerol skeletons analyzed by gas chromatography-mass spectrometry(GC-MS). The indirect methods have the advantage over direct methods of requiring only a few standard reagents. In 2013, AOCS registered three indirect methods, Cd 29a, Cd 29b, and Cd 29c, differentiated by their ester cleavage conditions ${ }^{18-20)}$. Method Cd 29a performs ester hydrolysis under acidic conditions, whereas method $\mathrm{Cd} 29 \mathrm{~b}$ uses alkaline conditions. Both methods require more than 10 hours for hydrolysis. Method Cd 29c performs ester hydrolysis under alkaline conditions with shorter reaction times, but cannot be used for the quantification of 2-MCPD-Es. These AOCS methods require both reference standards and deuterated internal standards in ester form to correct for ester cleavage efficiencies and unintended side reactions between analytes. Using reference standards in the ester form necessitates long hydrolysis times, as needed for the sample being analyzed, to construct calibration curves.

An indirect method using a lipase for ester cleavage was developed by Miyazaki et $a l^{21)}$ and was improved through preliminary and feasibility studies conducted by the MCPD subcommittee organized within JOCS for method validation $^{22)}$. In this method, ester hydrolysis is completed in 0.5 hour at room temperature. In addition, the method has the advantage that reference standards need not be in ester form, which eliminates the need for hydrolysis to construct calibration curves. Here, we report the results of a full collaborative study conducted by 13 participating laboratories to validate the improved method.

\section{EXPERIMENTAL}

\subsection{Reagents}

Of the ester standard reagents, 3-MCPD dioleate and glycidyl oleate were purchased from Wako Pure Chemical (Japan), and 2-MCPD dipalmitate was purchased from Toronto Research Chemicals (Canada). Of the free standard reagents, 3-MCPD and 3-monobromo-1,2-propanediol (3-MBPD) were purchased from Wako Pure Chemical, $3-\mathrm{MCPD}-d_{5}$ from CDN Isotopes (Canada), and 2-MCPD, 2 -MCPD- $d_{5}$, and 3-MBPD- $d_{5}$ from Toronto Research Chemicals. 3-MBPD and 3-MBPD- $d_{5}$ were used for the determinations of Gly-Es. Lipase AYS Amano (derived from Candida rugosa) was purchased from Wako Pure Chemical. These chemical reagents were distributed to all the laboratories participating in the collaborative study. The participating laboratories separately purchased phenylboronic acid (PBA; purity $\geq 97 \%$ ), special grade organic solvents, and salts.

A $30 \%(w / v)$ sodium bromide aqueous solution was prepared and adjusted to $\mathrm{pH} 5.0$ with citric acid and disodium hydrogen phosphate aqueous solutions. This solution was used to prepare a sodium bromide aqueous solution containing $90 \mathrm{U} / \mathrm{mL}$ lipase by dissolving Candida rugosa lipase. A PBA solution was prepared by dissolving $0.25 \mathrm{~g}$ 
PBA in $10 \mathrm{~mL}$ water/acetone mixed solution $(1: 19, v / v)$.

For the standard stock solutions, $300 \mu \mathrm{g} / \mathrm{mL}$ ethanol solutions were prepared for 3-MCPD, 2-MCPD, and 3-MBPD, and $200 \mu \mathrm{g} / \mathrm{mL}$ ethanol solutions were prepared for $3-\mathrm{MCPD}-d_{5}, 2-\mathrm{MCPD}-d_{5}$, and $3-\mathrm{MBPD}-d_{5}$ as internal standard stock solutions. These stock solutions could be stored at $\leq 20^{\circ} \mathrm{C}$ for at least three months. On the day of the study, each standard stock solution was diluted with the $30 \%$ sodium bromide aqueous solution to prepare $15 \mu \mathrm{g} / \mathrm{mL}$ standard mix I and $1.5 \mu \mathrm{g} / \mathrm{mL}$ standard mix II. Additionally, $2.0 \mu \mathrm{g} / \mathrm{mL}$ internal standard mix was prepared by combining each of the internal standard stock solutions and diluting it with the $30 \%$ sodium bromide aqueous solution.

\subsection{Oil samples}

Commercially available rapeseed, palm (liquid and solid), and rice bran oils were used as samples in the collaborative study. Extra virgin olive oil was chosen as a practice sample. Samples were spiked with ester standards, as shown in Table 1, dispensed into glass vials, and stored in the dark at room temperature. Each laboratory received one vial each of the five spiked samples (rapeseed No. 1, 4, and 5, palm (solid) No. 2, and rice bran No. 6) and one sample without spiking (palm (liquid) No. 3) under blind conditions, along with a practice sample (spiked extra virgin olive oil).

\subsection{Equipment}

A temperature-controlled water bath (DH-12; TAITEC, Japan), a vortex mixer(HM-10H; AS ONE, Japan), a centrifuge (Model 4000; Kubota, Japan), a nitrogen gas sprayer (EN-10/DTU-1BN; TAITEC), and a GC-MS (Quantum GC and TRACE GC Ultra; Thermo Fisher Scientific, USA), or equivalent apparatuses were used by each laboratory. For high-speed shaking, participants were asked to use one of the following shakers: I, one that shakes vertically mounted test tubes in an eccentric orbital motion at 1,800 rpm(e.g., CM-1000; Tokyo Rikakikai, Japan); II, one that shakes vertical mounted test tubes in a vertical reciprocating motion at 200 rpm (e.g., BF-40LF; TAITEC); or III, one that shakes test tubes mounted at $60^{\circ}$ from the axis in a horizontal reciprocating motion at 200-400 rpm (e.g., MW-1; AS ONE) (see Table 2).

\subsection{Procedures for analysis of oil samples and construc- tion of calibration curves}

The method developed by Miyazaki et $a l^{21)}$ and modified following the feasibility study by $\mathrm{JOCS}^{22)}$ was used in this study (Fig. 1). From each vial, $0.1 \mathrm{~g}$ of oil sample was weighed into separate $10 \mathrm{~mL}$ test tube, in duplicate. The oil sample was dissolved in $200 \mu \mathrm{L}$ of isooctane, with an exception of the solid oil sample, which was dissolved in 500 $\mu \mathrm{L}$ of isooctane and heated to $45-60^{\circ} \mathrm{C}$ for complete dissolution. After adding $3 \mathrm{~mL}$ of the $30 \%$ sodium bromide aqueous solution containing $90 \mathrm{U} / \mathrm{mL}$ lipase, the mixture was shaken by a high-speed shaker for $30 \mathrm{~min}$ at room temperature to hydrolyze the esters. The mixture was then heated in a water bath at $80^{\circ} \mathrm{C}$ for 10 min to achieve the bromination of Gly to 3-MBPD. The mixture was cooled to room temperature, and $50 \mu \mathrm{L}$ of $2.0 \mu \mathrm{g} / \mathrm{mL}$ internal standard mix was added. The mixture was washed twice with 3 $\mathrm{mL}$ of hexane by vortexing for $10 \mathrm{sec}$, and to the resulting aqueous layer, a $100 \mu \mathrm{L}$ PBA solution was added. After vortexing for a further $10 \mathrm{sec}, 3 \mathrm{~mL}$ of hexane was added, followed by high-speed shaking for 5-10 min. The resulting organic layer was collected, dehydrated with sodium sulfate, and concentrated to approximately $0.5-0.8 \mathrm{~mL}$ under a stream of nitrogen. After filtration through a 0.2

Table 1 Test samples prepared for collaborative study.

\begin{tabular}{|c|c|c|c|c|c|c|c|c|c|}
\hline \multirow{3}{*}{ No } & \multirow{3}{*}{ Oil } & & \multirow{3}{*}{$\begin{array}{l}\text { Iodine } \\
\text { values }\end{array}$} & \multicolumn{6}{|c|}{ Equiv. conc. $(\mathrm{mg} / \mathrm{kg})^{\mathrm{a})}$} \\
\hline & & & & \multicolumn{2}{|c|}{ 3-MCPD } & \multicolumn{2}{|c|}{ 2-MCPD } & \multicolumn{2}{|c|}{ Gly } \\
\hline & & & & blank $^{\text {b) }}$ & $\begin{array}{c}\text { amount } \\
\text { spiked }^{\mathrm{c}-1)}\end{array}$ & blank $^{\text {b) }}$ & $\begin{array}{c}\text { amount } \\
\text { spiked }^{\mathrm{c}-2)}\end{array}$ & blank $^{\text {b) }}$ & $\begin{array}{c}\text { amount } \\
\text { spiked }^{\mathrm{c}-3)}\end{array}$ \\
\hline 1,4 & Rapeseed & (High) & 111 & 0.08 & 3.50 & 0.05 & 3.68 & 0.20 & 4.44 \\
\hline 2 & Palm & (Solid) & 43 & 2.55 & 0.85 & 1.31 & 0.45 & 0.93 & 1.08 \\
\hline 3 & Palm & (Liquid) & 66 & 3.33 & $-{ }^{\text {d) }}$ & 1.82 & $-\mathrm{d})$ & 2.32 & - d) \\
\hline 5 & Rapeseed & (Low) & 111 & 0.08 & 0.54 & 0.05 & 0.56 & 0.20 & 0.61 \\
\hline 6 & Rice bran & & 104 & 0.28 & 1.09 & 0.14 & 1.15 & 0.78 & 2.77 \\
\hline 7 & Extra virgin olive & (for practice) & 82 & 0.04 & 4.17 & $-{ }^{e)}$ & 4.11 & 0.03 & 4.35 \\
\hline
\end{tabular}

a) Free form equivalent concentration.

b) Concentration measured by the coordinator.

c) Free form equivalent concentration spiked c-1) 3-MCPD dioleate, c-2) 2-MCPD dipalmitate, and c-3) Gly oleate.

d) Not spiked.

e) Not detected. The limit of detection for 2-MCPD corresponds to $0.007 \mathrm{mg} / \mathrm{kg}$ in $0.1 \mathrm{~g}$ oil samples. 
K. Koyama, K. Miyazaki and K. Abe et al.

Table 2 Equipment used for the collaborative study.

\begin{tabular}{|c|c|c|c|c|c|c|}
\hline \multirow{2}{*}{ Lab. code } & \multirow{2}{*}{$\begin{array}{l}\text { High-speed } \\
\text { Shaker }^{\text {a) }}\end{array}$} & \multicolumn{2}{|c|}{ Column } & \multicolumn{3}{|c|}{ GC-MS } \\
\hline & & Separation & Guard & Injection mode & & MS \\
\hline $\mathrm{A}$ & I & $\mathrm{VF}-5 \mathrm{~ms}$ & EZ-guard & Splitless & Agilent & 5975C TAD \\
\hline $\mathrm{B}$ & $\mathrm{I}$ & DB-5ms & Non & Splitless & Thermo & TSQ Quantum XLS \\
\hline $\mathrm{C}$ & III & DB-5ms & DuraGuard & Splitless, PVT & Shimadzu & GCMS-QP2010 \\
\hline $\mathrm{D}$ & II & HP-5ms & Non & Splitless & Agilent & 5975C inertXL \\
\hline $\mathrm{E}$ & I & $\mathrm{VF}-5 \mathrm{~ms}$ & EZ-guard & Splitless & Agilent & $5975 \mathrm{C}$ \\
\hline $\mathrm{F}$ & II & VF-5ms & EZ-guard & Splitless & Thermo & TRACE1310, ISQLT \\
\hline G & I & SLB- $5 \mathrm{~ms}$ & Non & Splitless & Agilent & $5975 \mathrm{C}$ inertXL \\
\hline $\mathrm{H}$ & III & $\mathrm{DB}-5 \mathrm{~ms}$ & Non & Splitless & Agilent & $5975 \mathrm{C}$ \\
\hline $\mathrm{I}$ & II & HP-5ms & Non & Splitless & Shimadzu & GCMS-QP2010 Plus \\
\hline $\mathrm{J}$ & $\mathrm{I}$ & VF-5ms & Non & Splitless & Varian & 320-MS \\
\hline $\mathrm{K}$ & II & $\mathrm{DB}-5 \mathrm{~ms}$ & Non & Splitless & Agilent & 5973 Network \\
\hline $\mathrm{L}$ & I & SLB-5ms & Non & Splitless & Shimadzu & GCMS-QP5050A \\
\hline $\mathrm{M}$ & II & $\mathrm{VF}-5 \mathrm{~ms}$ & EZ-guard & Splitless & Shimadzu & GCMS-QP2010 \\
\hline
\end{tabular}

a) Shaking conditions are described in Chapter 2.3.

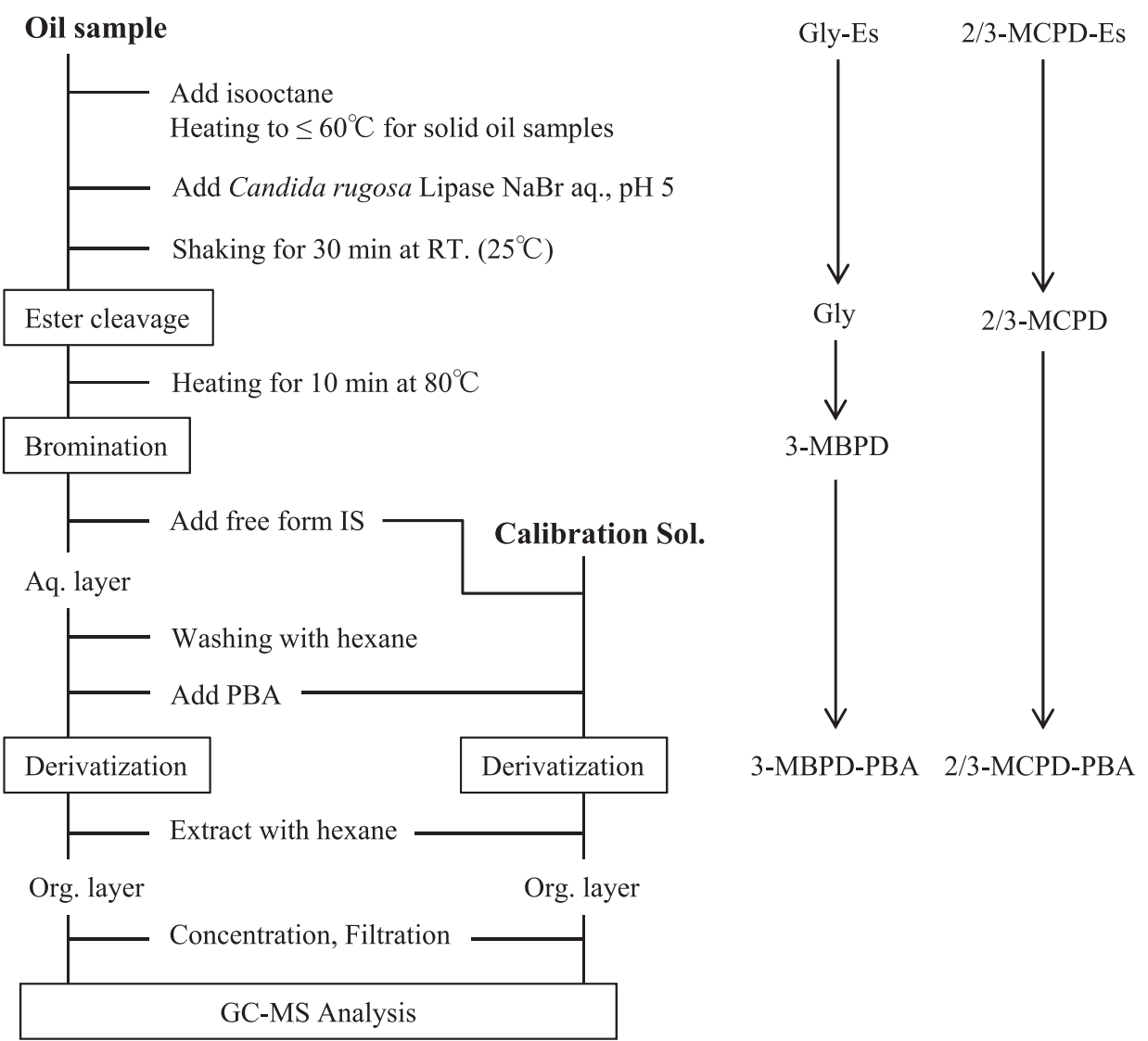

Fig. 1 Procedure flow of this analytical method. 
$\mu \mathrm{m}$ membrane filter, the samples were subjected to GC-MS analysis.

For the construction of calibration curves, the $1.5 \mu \mathrm{g} / \mathrm{mL}$ standard mix II in quantities of 5, 20, 50, and $100 \mu \mathrm{L}$, and the $15 \mu \mathrm{g} / \mathrm{mL}$ standard mix I in quantities of $20,35,50$, and $80 \mu \mathrm{L}$, were added into different $10 \mathrm{~mL}$ test tubes. To each test tube containing $0.0075,0.030,0.075,0.15,0.30,0.53$, 0.75 , or $1.2 \mu \mathrm{g}$ of each standard, a mixture of $50 \mu \mathrm{L}$ of the $2.0 \mu \mathrm{g} / \mathrm{mL}$ internal standard mix and $3 \mathrm{~mL}$ of the $30 \%$ sodium bromide aqueous solution was added, and PBA derivatization was performed as described above.

\subsection{GC-MS measurements}

A GC capillary column was used with a (5\%-phenyl) -methylpolysiloxane liquid phase, $30 \mathrm{~m}$ length, $0.25 \mathrm{~mm}$ internal diameter, and $0.25 \mu \mathrm{m}$ film thickness. Some laboratories used a guard column, and one laboratory used a programmed temperature vaporizer (PTV) function in the inlet, at their own discretion (see Table 2). The carrier gas was helium at a fixed flow rate of $1.2 \mathrm{~mL} / \mathrm{min}$. The sample was injected in splitless mode at $250^{\circ} \mathrm{C}$. The column oven temperature was held at $60^{\circ} \mathrm{C}$ for $1 \mathrm{~min}$, then raised to $150^{\circ} \mathrm{C}$ at $10^{\circ} \mathrm{C} / \mathrm{min}, 180^{\circ} \mathrm{C}$ at $3^{\circ} \mathrm{C} / \mathrm{min}$, and finally $300^{\circ} \mathrm{C}$ at $30^{\circ} \mathrm{C} /$ min, before being held at $300^{\circ} \mathrm{C}$ for $8 \mathrm{~min}$ (total run $=32$ min). MS was performed in positive electron ionization mode with an ion source temperature of $230^{\circ} \mathrm{C}$. Quantitative and qualitative analyses were performed by selective ion monitoring (SIM) using ions at $\mathrm{m} / z 147$ and 196 for the 3-MCPD derivative, 150 and 201 for the 3 -MCPD- $d_{5}$ derivative, 196 and 198 for the 2-MCPD derivative, 201 and 203 for the 2-MCPD- $d_{5}$ derivative, 147 and 240 for the 3-MBPD derivative, and 150 and 245 for the $3-\mathrm{MBPD}-d_{5}$ derivative.

\subsection{Collaborative Study}

This collaborative study was performed by thirteen laboratories in Japan. The participants analyzed the practice sample first, followed by the six blind samples (Nos. 1-6 in Table 1) in duplicate. The free-form equivalent concentrations of 3-MCPD, 2-MCPD, and Gly were calculated using the internal standards and the calibration curves, and were reported to the coordinator (corresponding author). The coordinator analyzed the distributed samples and the corresponding blank oils (not spiked) in duplicate, and confirmed the homogeneity of the oil samples by duplicate analysis of six vials selected randomly from the distributed samples of rapeseed oil (No. 1) and rice bran oil (No. 6), respectively.

\section{RESULTS AND DISCUSSION}

\subsection{Preliminary performance evaluation of the analytical method by the coordinator}

Typical GC-MS chromatograms of the PBA derivatives of
3-MCPD, 2-MCPD, and 3-MBPD (brominated Gly) obtained by the coordinator are shown in Figs. 2 and 3. The analytes in the standard and the oil sample were separated without interruption. The distributed oil samples were spiked with ester standards to blank oils. As shown in Table 3, the homogeneities of the two oil samples were confirmed by one-way analysis of variance. The homogeneities of the other oil samples were considered guaranteed because they were prepared in the same manner. As shown in Table 4 , satisfactory recovery rates, in the range $95.1-113.7 \%$, were obtained for all spiked samples. These results suggested that the method was ready for the collaborative study.

\subsection{Collaborative study}

The results for the free-form equivalent concentrations $(\mathrm{mg} / \mathrm{kg})$ of all analytes in all oil samples analyzed by all participant laboratories are shown in Table 5a-c, along with the statistical parameters. Outlier data determined by Cochran's test are indicated with asterisks. Dixon's test showed no outlier or straggler data. After removal of the outlier data, the repeatability and reproducibility were calculated for each analyte in each oil sample.

The repeatability relative standard deviations $\left(R S D_{r}\right)$ for the liquid oils, i.e., rapeseed oils (No. 1, 4, and 5), liquid palm oil (No. 3), and rice bran oil (No. 6), were $<4.2 \%$ for 3 -MCPD, $<3.4 \%$ for 2 -MCPD, and $<3.4 \%$ for Gly. The $R S D_{r}$ values for solid palm oil (No.2) were $<8.4 \%$ for 3 -MCPD, $<1.8 \%$ for $2-\mathrm{MCPD}$, and $<2.8 \%$ for Gly. The $R S D_{r}$ for 3 -MCPD was slightly larger in solid palm oil. The reproducibility relative standard deviations $\left(R S D_{R}\right)$ for liquid oils were $<18.0 \%$ for 3 -MCPD, $<11.7 \%$ for $2-\mathrm{MCPD}$, and $<7.5 \%$ for Gly. The large $R S D_{R}$ for $3-\mathrm{MCPD}$ in rapeseed oil (No. 5) was considered to be due to the low analyte concentration. The $R S D_{R}$ values for solid palm oil(No.2) were $<18.0 \%$ for $3-\mathrm{MCPD},<8.6 \%$ for $2 \mathrm{MCPD}$, and $<$ $7.7 \%$ for Gly. These $R S D_{r}$ and $R S D_{R}$ values were similar or smaller than $R S D_{r}(3.5-9.9 \%)$ and $R S D_{R}(6.4-31.8 \%)$ reported for palm oil samples containing $1-11 \mathrm{mg} / \mathrm{kg}$ in the collaborative study conducted by AOAC in 2013 for three indirect methods ${ }^{23)}$. Horwitz ratios (HORRAT) for all oils were $<1.33$ for 3 -MCPD, $<0.80$ for $2-\mathrm{MCPD}$, and $<0.53$ for Gly. The Horwitz ratio of $<2$ means that the current method meets one of the acceptability criteria for recently adopted chemical methods for analysis of AOAC INTERNATIONAL $^{24,25)}$

Two identical rapeseed oil samples (No. 1 and 4)were analyzed under blind conditions to check for possible bias in the analysis potentially caused by an unconscious will for data adjustment, even when taking samples from the same unlabeled vial. When calculated using only the first data of the duplicate analyses of No. 1 and 4, respectively, as a blind duplicate, the $R S D_{r}$ values were $3.5 \%$ for 3-MCPD, 2.0\% for 2-MCPD, and 2.0\% for Gly. As these 

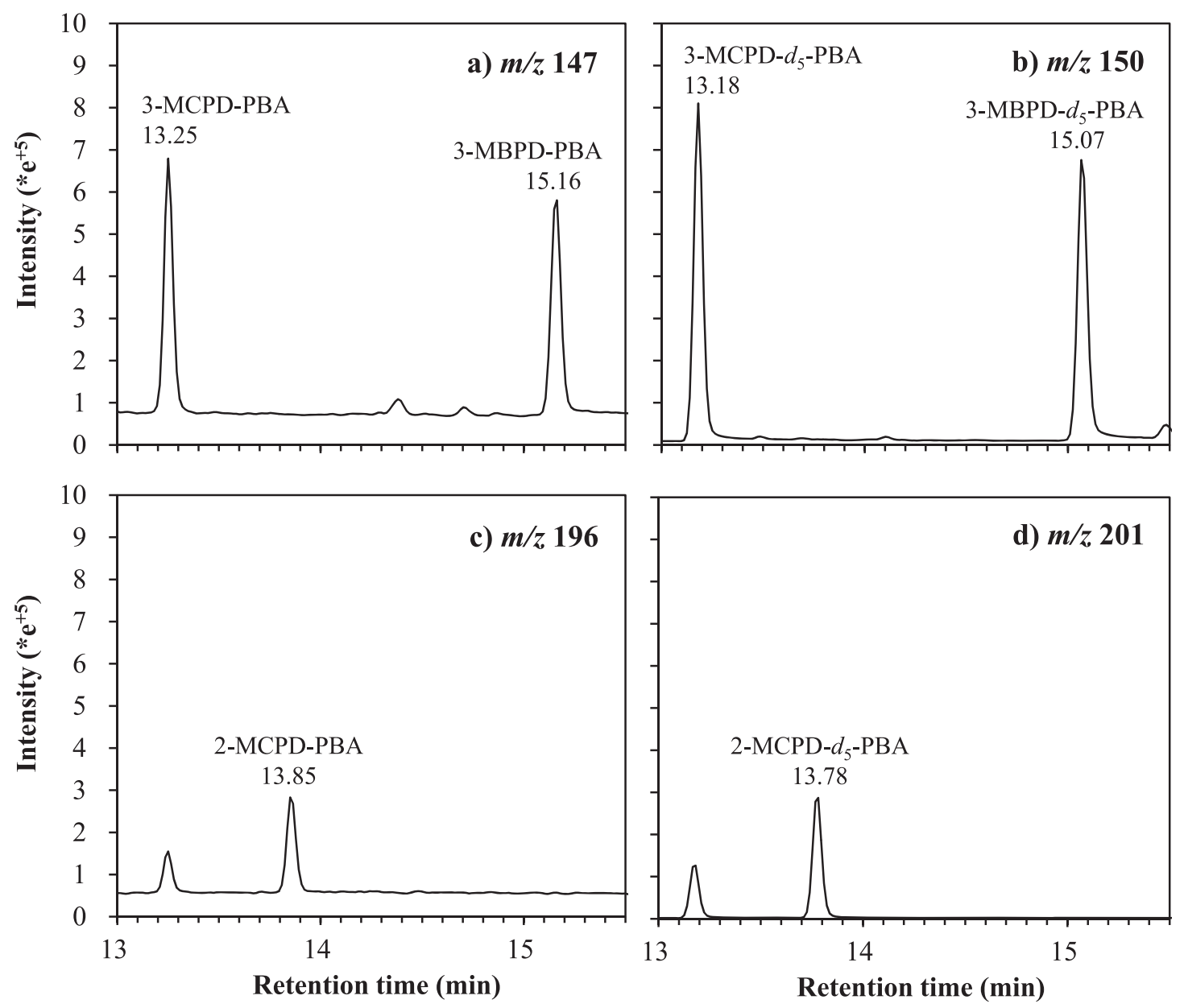

Fig. 2 GC-MS profiles of phenylboronic acid (PBA) derivatives resulting from free type standards with $0.075 \mu$ g; a) 3-MCPD and 3-MBPD, b) 3-MCPD- $d_{5}$ and 3-MBPD- $d_{5}$, c) $2-\mathrm{MCPD}$, and d) $2-\mathrm{MCPD}-d_{5}$.

values were in the same range as those calculated for No. 1 and 4 independently (Table $5 \mathrm{a}$ and $5 \mathrm{~b}$ ), it was considered that no bias was observed.

The solid palm oil sample(No. 2) had an iodine value of 43 (Table 1) and a rising melting point of $50^{\circ} \mathrm{C}$. The $R S D_{R}$ for 3-MCPD in the solid palm oil was $18.0 \%$, which was slightly higher than those of other oil samples containing similar analyte amounts (No. 1, 3, 4, and 6). As detailed in the experimental section, participating laboratories were instructed to dissolve the solid oil sample in isooctane by heating the sample to $45-60^{\circ} \mathrm{C}$. Three laboratories (C, F, and $\mathrm{M}$ ), in which the sample was heated to $50^{\circ} \mathrm{C}$ or lower, reported lower 3-MCPD concentrations than the other laboratories, in which the sample was heated to $60^{\circ} \mathrm{C}$. These lower concentration results for 3-MCPD-Es in the solid oil sample were suspected to be due to incomplete dissolution. Thus, for complete dissolution, a temperature at $60^{\circ} \mathrm{C}$ would be recommended. As this indirect method utilizes enzymatic activity, the reaction solvent contained more water than those in the three indirect AOCS official methods. While the water content might hinder the disso- lution of oils with higher melting points, it was found that this could be overcome by heating and vigorous shaking. Thus, the current method is expected to be applicable to a wide range of oils and fats.

The concentrations of all three analytes in the rapeseed oil sample (No. 5) were in the range $0.61-0.87 \mathrm{mg} / \mathrm{kg}$ (Table $5 \mathrm{c}$ ), which was within the range of concentrations normally found in many commercial oils. The $R S D_{r}$ values for the rapeseed oil sample were $2.6 \%$ for $3-\mathrm{MCPD},<3.4 \%$ for 2-MCPD, and $1.9 \%$ for Gly, which were considered sufficiently small. The $R S D_{R}$ values were $18.0 \%$ for $3-\mathrm{MCPD}$, $9.7 \%$ for 2 -MCPD, and $7.5 \%$ for Gly. The larger $R S D_{R}$ value of 3-MCPD compared with those of 2-MCPD and Gly was attributed to the selected-ion monitoring chromatogram of the 3-MCPD derivative, which was probably influenced by general background contaminants such as column bleed. The influence appeared to be more pronounced in samples containing low levels of analytes. The Horwitz ratios were also less than 2, calculated as 1.05 for 3-MCPD, 0.57 for 2-MCPD, and 0.46 for Gly, indicating that the current method could be suitable for the determination of 3-MCPD, 

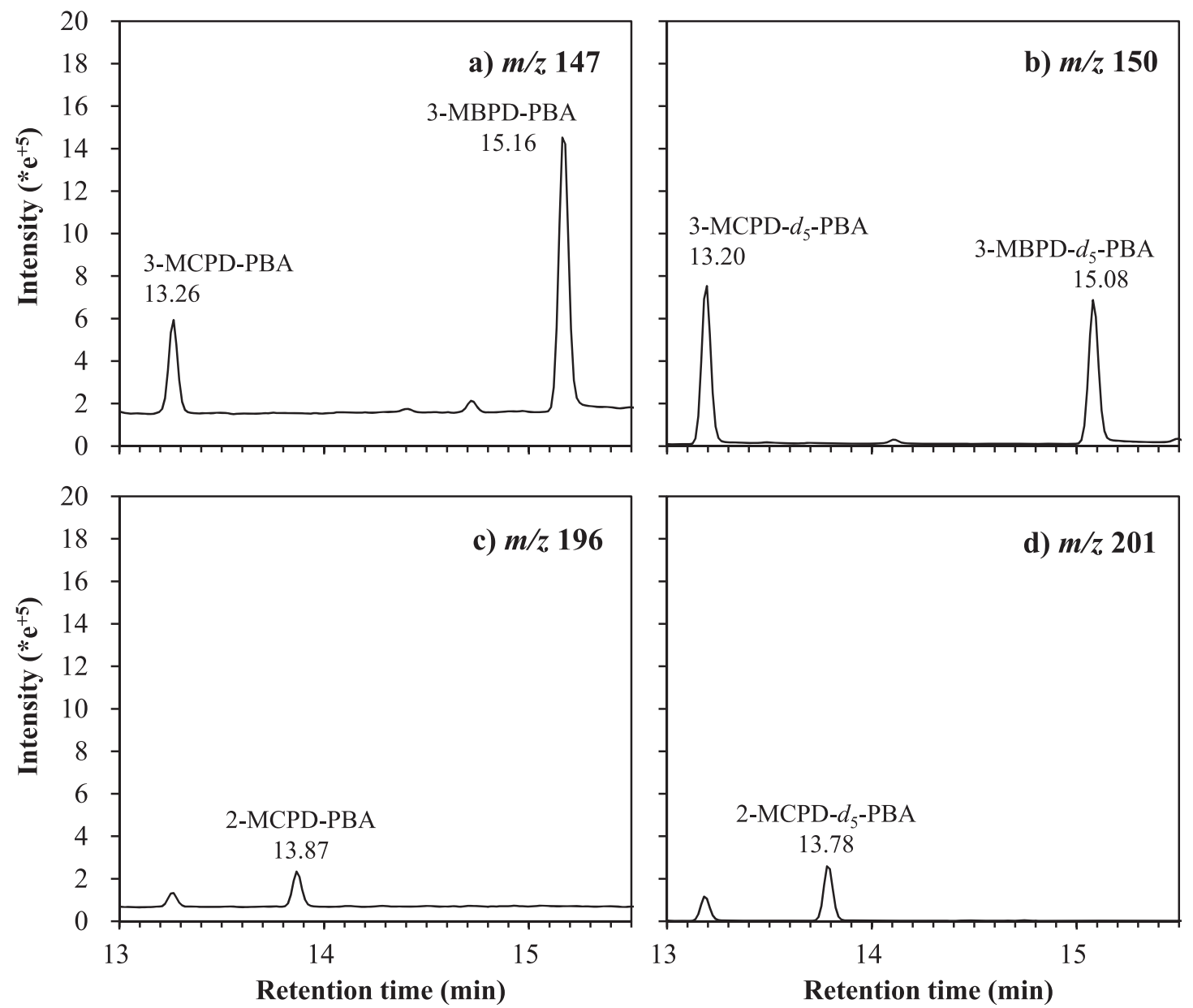

Fig. 3 GC-MS profiles of phenylboronic acid (PBA) derivatives resulting from solid palm oil sample(No. 2); a) 3-MCPD and $3-\mathrm{MBPD}, \mathrm{b}) 3-\mathrm{MCPD}-d_{5}$ and 3-MBPD- $\left.d_{5}, \mathrm{c}\right) 2-\mathrm{MCPD}$, and d) $2-\mathrm{MCPD}-d_{5}$.

Table 3 Homogeneity of oil samples by one-way analysis of variance.

\begin{tabular}{|c|c|c|c|c|c|}
\hline No & Oil & Parameter & 3-MCPD & 2-MCPD & Gly \\
\hline \multirow{2}{*}{1,4} & Rapeseed (High) & Measured mean $(\mathrm{mg} / \mathrm{kg})^{\mathrm{a})}$ & 3.31 & 3.62 & 4.92 \\
\hline & & $P$-value & 0.61 & 0.22 & 0.27 \\
\hline \multirow[t]{2}{*}{6} & Rice bran & Measured mean $(\mathrm{mg} / \mathrm{kg})^{\mathrm{a})}$ & 1.48 & 1.41 & 3.64 \\
\hline & & $P$-value & 0.15 & 0.19 & 0.37 \\
\hline
\end{tabular}

a) A coordinator analyzed randomly taken six vials of samples in duplicate.

Table 4 Recovery from test sample shown in Table 1.

\begin{tabular}{cllccc}
\hline \multirow{2}{*}{ No } & \multirow{2}{*}{ Oil } & \multicolumn{3}{c}{ Recovery (\%) } \\
\cline { 4 - 6 } & & & 3-MCPD & 2-MCPD & Gly \\
\hline 1,4 & Rapeseed & (High) & $102.6,105.8$ & $102.1,106.5$ & $106.5,107.3$ \\
2 & Palm & (Solid) & $101.2,103.9$ & $105.4,107.0$ & $106.7,104.7$ \\
5 & Rapeseed & (Low) & $102.6,104.0$ & $100.7,100.0$ & $104.0,102.4$ \\
6 & Rice bran & & $103.6,113.7$ & $103.4,105.1$ & $106.4,105.0$ \\
7 & Extra virgin olive & (for practice) & $106.9,108.2$ & $95.1,95.1$ & $109.8,109.2$ \\
\hline
\end{tabular}


K. Koyama, K. Miyazaki and K. Abe et al.

Table 5a Statistical parameters by collaborative study obtained from 13 laboratories.

\begin{tabular}{|c|c|c|c|c|c|c|c|}
\hline \multirow{3}{*}{ Laboratory } & \multirow{3}{*}{ Entry } & \multicolumn{6}{|c|}{ Equiv. conc. (mg/kg) } \\
\hline & & \multicolumn{3}{|c|}{ No.1, Rapeseed (High) } & \multicolumn{3}{|c|}{ No.2, Palm (Solid) } \\
\hline & & 3-MCPD & 2-MCPD & Gly & 3-MCPD & 2-MCPD & Gly \\
\hline \multirow[t]{2}{*}{$\mathrm{A}$} & 1 & 3.28 & 3.94 & 5.11 & 3.28 & 1.82 & 2.13 \\
\hline & 2 & 3.46 & 4.01 & 5.10 & 3.23 & 1.87 & 2.19 \\
\hline \multirow[t]{2}{*}{$\mathrm{B}$} & 1 & 3.28 & 3.77 & 4.99 & 3.31 & 1.83 & 2.13 \\
\hline & 2 & 3.43 & 3.84 & 5.07 & 3.42 & 1.80 & 2.11 \\
\hline \multirow[t]{2}{*}{$\mathrm{C}$} & 1 & $1.89 *$ & 3.07 & 4.75 & 1.34 & $1.35^{*}$ & 1.81 \\
\hline & 2 & $2.52 *$ & 3.35 & 4.65 & 2.00 & $1.59 *$ & 1.78 \\
\hline \multirow[t]{2}{*}{$\mathrm{D}$} & 1 & 3.96 & 4.04 & 5.05 & 3.04 & 1.91 & 2.18 \\
\hline & 2 & 3.78 & 4.05 & 5.39 & 2.91 & 1.88 & 2.21 \\
\hline \multirow[t]{2}{*}{$\mathrm{E}$} & 1 & 3.56 & 4.10 & 4.70 & 3.04 & 1.88 & 2.00 \\
\hline & 2 & 3.57 & 4.28 & 4.77 & 3.35 & 1.97 & 1.87 \\
\hline \multirow[t]{2}{*}{$\mathrm{F}$} & 1 & 3.42 & 3.85 & 5.34 & 2.70 & 1.80 & 2.04 \\
\hline & 2 & 3.50 & 4.02 & 5.63 & 2.63 & 1.78 & 2.20 \\
\hline \multirow[t]{2}{*}{ G } & 1 & 3.63 & 4.09 & 5.29 & 3.64 & 2.08 & 2.29 \\
\hline & 2 & 3.80 & 3.99 & 5.39 & 3.93 & 2.10 & 2.36 \\
\hline \multirow[t]{2}{*}{$\mathrm{H}$} & 1 & 3.51 & 3.77 & 4.94 & 3.15 & 1.74 & 1.95 \\
\hline & 2 & 3.51 & 3.73 & 4.92 & 3.18 & 1.74 & 1.95 \\
\hline \multirow[t]{2}{*}{ I } & 1 & 3.55 & 3.91 & 4.99 & 3.25 & 1.80 & 2.06 \\
\hline & 2 & 3.50 & 3.90 & 4.90 & 3.24 & 1.85 & 2.03 \\
\hline \multirow[t]{2}{*}{$\mathrm{J}$} & 1 & $3.54 *$ & 3.69 & 4.79 & 3.36 & $2.38^{*}$ & $2.90 *$ \\
\hline & 2 & $3.02 *$ & 3.59 & 5.30 & 2.45 & $1.64 *$ & $2.12 *$ \\
\hline \multirow[t]{2}{*}{$\mathrm{K}$} & 1 & 3.53 & 3.77 & 4.89 & 3.06 & 1.70 & 1.85 \\
\hline & 2 & 3.53 & 3.90 & 4.65 & 3.18 & 1.69 & 1.83 \\
\hline \multirow[t]{2}{*}{$\mathrm{L}$} & 1 & 3.14 & 3.54 & 4.99 & 3.73 & 1.69 & 2.04 \\
\hline & 2 & 3.26 & 3.66 & 5.43 & 3.41 & 1.75 & 2.20 \\
\hline \multirow[t]{2}{*}{$\mathrm{M}$} & 1 & 3.12 & 4.78 & 5.01 & 2.54 & 2.18 & 2.05 \\
\hline & 2 & 3.13 & 4.74 & 4.84 & 2.87 & 2.24 & 2.05 \\
\hline \multicolumn{2}{|c|}{$\begin{array}{l}\text { Number of laboratories retained } \\
\text { after elimination of outliers }\end{array}$} & 11 & 13 & 13 & 13 & 11 & 12 \\
\hline \multicolumn{2}{|l|}{ Mean } & 3.48 & 3.90 & 5.03 & 3.05 & 1.87 & 2.06 \\
\hline \multicolumn{8}{|l|}{ Repeatability } \\
\hline \multicolumn{2}{|c|}{ Standard deviation $\left(S D_{r}\right)$} & 0.08 & 0.09 & 0.17 & 0.26 & 0.03 & 0.06 \\
\hline \multicolumn{2}{|c|}{$\begin{array}{l}\text { Relative standard deviation } \\
\left(R S D_{r}\right)\end{array}$} & 2.31 & 2.32 & 3.44 & 8.38 & 1.77 & 2.77 \\
\hline \multicolumn{8}{|c|}{ Reproducibility } \\
\hline \multicolumn{2}{|c|}{ Standard deviation $\left(S D_{R}\right)$} & 0.22 & 0.36 & 0.27 & 0.55 & 0.16 & 0.16 \\
\hline \multicolumn{2}{|c|}{$\begin{array}{l}\text { Relative standard deviation } \\
\left(R S D_{R}\right)\end{array}$} & 6.35 & 9.31 & 5.28 & 18.03 & 8.55 & 7.65 \\
\hline Horwitz ratio & & 0.48 & 0.71 & 0.42 & 1.33 & 0.59 & 0.53 \\
\hline
\end{tabular}

*) Outlier data as determined by the Cochran test. Dixon test revealed no outlier data. 
Collaborative Study of Indirect Enzymatic Method of MCPD and Glycidyl esters

Table 5b Statistical parameters by collaborative study obtained from 13 laboratories.

\begin{tabular}{|c|c|c|c|c|c|c|c|}
\hline \multirow{3}{*}{ Laboratory } & \multirow{3}{*}{ Entry } & \multicolumn{6}{|c|}{ Equiv. conc. (mg/kg) } \\
\hline & & \multicolumn{3}{|c|}{ No.3, Palm (Liquid) } & \multicolumn{3}{|c|}{ No.4, Rapeseed (High) } \\
\hline & & 3-MCPD & 2-MCPD & Gly & 3-MCPD & 2-MCPD & Gly \\
\hline \multirow[t]{2}{*}{ A } & 1 & 2.92 & 1.80 & 2.25 & 3.17 & 3.76 & 5.05 \\
\hline & 2 & 3.04 & 1.82 & 2.31 & 3.00 & 3.67 & 4.85 \\
\hline \multirow[t]{2}{*}{$\mathrm{B}$} & 1 & 3.12 & 1.79 & 2.33 & 3.41 & 3.71 & 4.99 \\
\hline & 2 & 2.97 & 1.66 & 2.30 & 3.47 & 3.71 & 5.05 \\
\hline \multirow[t]{2}{*}{$\mathrm{C}$} & 1 & $1.91^{*}$ & $1.44 *$ & 1.99 & 2.34 & 3.13 & 4.92 \\
\hline & 2 & $3.34 *$ & $1.79 *$ & 1.86 & 2.19 & 3.27 & 4.78 \\
\hline \multirow[t]{2}{*}{$\mathrm{D}$} & 1 & 3.46 & 1.90 & 2.58 & 3.52 & 3.95 & 5.13 \\
\hline & 2 & 3.46 & 1.81 & 2.49 & 3.57 & 3.98 & 5.31 \\
\hline \multirow[t]{2}{*}{$\mathrm{E}$} & 1 & 3.30 & 1.94 & 2.04 & 3.59 & 4.29 & 4.64 \\
\hline & 2 & 3.24 & 1.93 & 2.07 & 3.56 & 4.18 & 4.68 \\
\hline \multirow[t]{2}{*}{$\mathrm{F}$} & 1 & 2.90 & 1.70 & 2.24 & 3.31 & 3.96 & 4.97 \\
\hline & 2 & 3.28 & 1.84 & 2.35 & 3.36 & 3.89 & 5.12 \\
\hline \multirow[t]{2}{*}{ G } & 1 & 3.53 & 1.96 & 2.45 & 3.70 & 4.00 & 5.32 \\
\hline & 2 & 3.37 & 1.97 & 2.40 & 3.87 & 4.10 & 5.39 \\
\hline \multirow[t]{2}{*}{$\mathrm{H}$} & 1 & 3.04 & 1.64 & 2.12 & 3.46 & 3.73 & 5.06 \\
\hline & 2 & 3.16 & 1.68 & 2.22 & 3.47 & 3.79 & 5.06 \\
\hline \multirow[t]{2}{*}{ I } & 1 & 3.17 & 1.75 & 2.25 & 3.45 & 3.87 & 4.89 \\
\hline & 2 & 3.19 & 1.75 & 2.21 & 3.58 & 3.80 & 4.96 \\
\hline \multirow[t]{2}{*}{$\mathrm{J}$} & 1 & $3.21 *$ & $1.76^{*}$ & $1.91 *$ & 3.51 & 3.72 & 4.82 \\
\hline & 2 & $2.39 *$ & $1.28 *$ & $1.58^{*}$ & 3.57 & 3.76 & 4.41 \\
\hline \multirow[t]{2}{*}{$\mathrm{K}$} & 1 & 3.25 & 1.66 & 2.21 & 3.55 & 3.76 & 4.71 \\
\hline & 2 & 3.33 & 1.70 & 2.24 & 3.40 & 3.74 & 4.60 \\
\hline \multirow[t]{2}{*}{$\mathrm{L}$} & 1 & 3.27 & 1.38 & 2.29 & 3.44 & 3.46 & 5.64 \\
\hline & 2 & 3.45 & 1.46 & 2.29 & 3.45 & 3.22 & 5.62 \\
\hline \multirow[t]{2}{*}{ M } & 1 & 2.98 & 2.20 & 2.29 & 3.14 & 4.60 & 4.95 \\
\hline & 2 & 2.98 & 2.27 & 2.27 & 2.83 & 4.44 & 4.89 \\
\hline \multicolumn{2}{|c|}{$\begin{array}{l}\text { Number of laboratories retained } \\
\text { after elimination of outliers }\end{array}$} & 11 & 11 & 12 & 13 & 13 & 13 \\
\hline \multicolumn{2}{|l|}{ Mean } & 3.20 & 1.80 & 2.25 & 3.34 & 3.83 & 4.99 \\
\hline \multicolumn{8}{|l|}{ Repeatability } \\
\hline \multicolumn{2}{|c|}{ Standard deviation $\left(S D_{r}\right)$} & 0.11 & 0.05 & 0.05 & 0.09 & 0.08 & 0.11 \\
\hline \multicolumn{2}{|c|}{$\begin{array}{l}\text { Relative standard deviation } \\
\left(R S D_{r}\right)\end{array}$} & 3.42 & 2.93 & 2.21 & 2.79 & 2.01 & 2.20 \\
\hline \multicolumn{8}{|c|}{ Reproducibility } \\
\hline \multicolumn{2}{|c|}{ Standard deviation $\left(S D_{R}\right)$} & 0.19 & 0.21 & 0.16 & 0.39 & 0.35 & 0.30 \\
\hline \multicolumn{2}{|c|}{$\begin{array}{l}\text { Relative standard deviation } \\
\left(R S D_{R}\right)\end{array}$} & 6.03 & 11.66 & 7.18 & 11.68 & 9.02 & 5.98 \\
\hline Horwitz ratio & & 0.45 & 0.80 & 0.51 & 0.88 & 0.69 & 0.48 \\
\hline
\end{tabular}

*) Outlier data as determined by the Cochran test. Dixon test revealed no outlier data. 
K. Koyama, K. Miyazaki and K. Abe et al.

Table 5c Statistical parameters by collaborative study obtained from 13 laboratories.

\begin{tabular}{|c|c|c|c|c|c|c|c|}
\hline \multirow{3}{*}{ Laboratory } & \multirow{3}{*}{ Entry } & \multicolumn{6}{|c|}{ Equiv. conc. (mg/kg) } \\
\hline & & \multicolumn{3}{|c|}{ No.5, Rapeseed (Low) } & \multicolumn{3}{|c|}{ No.6, Rice bran } \\
\hline & & 3-MCPD & 2-MCPD & Gly & 3-MCPD & 2-MCPD & Gly \\
\hline \multirow[t]{2}{*}{$\mathrm{A}$} & 1 & 0.57 & 0.67 & 0.90 & 1.36 & 1.42 & 3.69 \\
\hline & 2 & 0.56 & 0.68 & 0.91 & 1.34 & 1.44 & 3.86 \\
\hline \multirow[t]{2}{*}{$\mathrm{B}$} & 1 & 0.58 & 0.57 & 0.89 & 1.38 & 1.38 & 3.85 \\
\hline & 2 & 0.56 & 0.57 & 0.91 & 1.32 & 1.32 & 3.88 \\
\hline \multirow[t]{2}{*}{$\mathrm{C}$} & 1 & $0.24 *$ & $0.46^{*}$ & 0.77 & $0.82 *$ & 1.22 & 3.50 \\
\hline & 2 & $0.94 *$ & $0.70 *$ & 0.75 & $1.80 *$ & 1.36 & 3.54 \\
\hline \multirow[t]{2}{*}{$\mathrm{D}$} & 1 & 0.63 & 0.65 & 1.01 & 1.29 & 1.36 & 3.86 \\
\hline & 2 & 0.61 & 0.66 & 0.97 & 1.42 & 1.44 & 3.98 \\
\hline \multirow[t]{2}{*}{$\mathrm{E}$} & 1 & 0.58 & 0.66 & 0.83 & 1.36 & 1.52 & 3.53 \\
\hline & 2 & 0.55 & 0.58 & 0.78 & 1.34 & 1.56 & 3.29 \\
\hline \multirow[t]{2}{*}{$\mathrm{F}$} & 1 & 0.56 & 0.67 & $0.74 *$ & 1.36 & 1.37 & 3.71 \\
\hline & 2 & 0.55 & 0.68 & $0.91 *$ & 1.32 & 1.36 & 3.83 \\
\hline \multirow[t]{2}{*}{ G } & 1 & 0.83 & 0.75 & 0.93 & 1.40 & 1.27 & 3.45 \\
\hline & 2 & 0.84 & 0.73 & 0.96 & 1.58 & 1.36 & 3.70 \\
\hline \multirow[t]{2}{*}{$\mathrm{H}$} & 1 & 0.62 & 0.61 & 0.84 & 1.36 & 1.32 & 3.83 \\
\hline & 2 & 0.62 & 0.59 & 0.83 & 1.36 & 1.29 & 3.59 \\
\hline \multirow[t]{2}{*}{ I } & 1 & 0.59 & 0.59 & 0.83 & 1.33 & 1.30 & 3.73 \\
\hline & 2 & 0.58 & 0.57 & 0.83 & 1.35 & 1.31 & 3.69 \\
\hline \multirow[t]{2}{*}{$\mathrm{J}$} & 1 & $0.60 *$ & 0.57 & $0.81 *$ & 1.40 & 1.25 & 3.34 \\
\hline & 2 & $1.48 *$ & 0.61 & $0.95^{*}$ & 1.38 & 1.27 & 3.42 \\
\hline \multirow[t]{2}{*}{$\mathrm{K}$} & 1 & 0.56 & 0.56 & 0.85 & 1.36 & 1.27 & 3.69 \\
\hline & 2 & 0.54 & 0.57 & 0.85 & 1.35 & 1.30 & 3.51 \\
\hline \multirow[t]{2}{*}{$\mathrm{L}$} & 1 & 0.76 & 0.56 & 0.89 & 1.61 & 1.24 & 3.56 \\
\hline & 2 & 0.81 & 0.51 & 0.86 & 1.77 & 1.36 & 3.86 \\
\hline \multirow[t]{2}{*}{ M } & 1 & 0.45 & 0.62 & 0.86 & 1.23 & 1.62 & 3.76 \\
\hline & 2 & 0.46 & 0.63 & 0.85 & 1.22 & 1.58 & 3.77 \\
\hline \multicolumn{2}{|c|}{$\begin{array}{l}\text { Number of laboratories retained } \\
\text { after elimination of outliers }\end{array}$} & 11 & 12 & 11 & 12 & 13 & 13 \\
\hline \multicolumn{2}{|l|}{ Mean } & 0.61 & 0.62 & 0.87 & 1.38 & 1.37 & 3.67 \\
\hline \multicolumn{8}{|l|}{ Repeatability } \\
\hline \multicolumn{2}{|c|}{ Standard deviation $\left(S D_{r}\right)$} & 0.02 & 0.02 & 0.02 & 0.06 & 0.05 & 0.12 \\
\hline \multicolumn{2}{|c|}{$\begin{array}{l}\text { Relative standard deviation } \\
\left(R S D_{r}\right)\end{array}$} & 2.62 & 3.41 & 1.89 & 4.23 & 3.41 & 3.23 \\
\hline \multicolumn{8}{|c|}{ Reproducibility } \\
\hline \multicolumn{2}{|c|}{ Standard deviation $\left(S D_{R}\right)$} & 0.11 & 0.06 & 0.07 & 0.12 & 0.11 & 0.18 \\
\hline \multicolumn{2}{|c|}{$\begin{array}{l}\text { Relative standard deviation } \\
\left(R S D_{R}\right)\end{array}$} & 18.03 & 9.73 & 7.49 & 8.74 & 7.93 & 5.02 \\
\hline Horwitz ratio & & 1.05 & 0.57 & 0.46 & 0.57 & 0.52 & 0.38 \\
\hline
\end{tabular}

*) Outlier data as determined by the Cochran test. Dixon test revealed no outlier data. 
2-MCPD, and Gly at low concentrations in various oil samples. The limit of quantification (LOQ) was calculated as $L O Q=10 \sigma / \mathrm{S}$, where $\sigma$ is the residual standard deviation and $\mathrm{S}$ is the slope of the calibration curve. The LOQ values from participating laboratories were calculated as 1-46 ng (14 ng average) for 3-MCPD, 3-59 ng (14 ng average) for 2-MCPD, and 1-41 ng (6 ng average) for Gly. The highest LOQ for 2-MCPD, $59 \mathrm{ng}$, corresponded with $0.59 \mathrm{mg} / \mathrm{kg}$ in a $0.1 \mathrm{~g}$ oil sample. The lowest concentration found in all oil samples was $0.62 \mathrm{mg} / \mathrm{kg}$ for $2-\mathrm{MCPD}$ in the rapeseed oil sample (No. 5). Therefore, all three analytes in all oil samples were considered to be within the LOQ.

Participating laboratories used their own equipment and instruments for the analysis. In a previous report, we described the importance in the conditions of the high-speed shaker used for ester cleavage and solvent extraction. Participating laboratories were asked to choose one of the three sets of conditions regarding the mode and speed of shaking, and the test tube mounting angle, as shown in Table 2. Although there were considerable variations in high-speed shakers and GC-MS systems used, including the capillary columns, the $R S D_{R}$ values were all within the acceptable range. Thus, the current method can be used for rapid quantitative analysis of esters of 3-MCPD, 2-MCPD, and Gly in edible oils and fats by laboratories equipped with standard analytical instruments.

\section{CONCLUSION}

A collaborative study was conducted to evaluate an indirect enzymatic method for the analysis of fatty acid esters of 3-monochloro-1,2-propanediol (3-MCPD), 2-monochloro-1,3-propanediol (2-MCPD), and glycidol (Gly) in edible oils and fats. Thirteen laboratories analyzed liquid palm, solid palm, rapeseed, and rice bran oils containing 3-MCPD, 2-MCPD, and Gly at 0.6-5.0 mg/kg levels as freeform equivalents. The repeatability $\left(R S D_{r}\right)$ were $<5 \%$ for the five liquid oil samples and $8 \%$ for the solid oil sample. The reproducibility $\left(R S D_{R}\right)$ ranged from $5 \%$ to $18 \%$ for all oil samples, which were considered satisfactory because the Horwitz ratios were $\leq 1.3 \%$ for all three analytes in all oil samples. This method is applicable to the quantification of 3-MCPD, 2-MCPD, and Gly esters in edible oils.

\section{ACKNOWLEDGEMENT}

This study was carried out under the guidance of the committee of the of JOCS standard methods. We also thank all the participants in this study for acquiring data.

\section{References}

1) Velišek, J.; Davidek, J.; Hajšlová, J.; Kubelka, V.; Janiček, G.; Mánková, B. Chlorohydrins in protein hydrolysates.Z. Lebensm. Unters Forsch. 167, 241-244 (1978).

2) Cordex, Code of Practice for the Reduction of 3-Monochloropropane-1,2-diol(3-MCPD) during the Production of Acid-Hydrolyzed Vegetable Protein (AcidHVPs) and Products that Contain Acid- HVPs. CAC/ RCP, 64 (2008).

3) Svejkovská, B.; Novotný, O.; Divinová, V.; Réblová, Z.; Doležal, M.; Velíšek, J. Esters of 3-chloropropane-1,2diol in foodstuffs. Czech J. Food Sci. 22, 190-196 (2004).

4) Zelinková, Z.; Svejkovská, B.; Velíšek, J.; Doležal, M. Fatty acid esters of 3-chloropropane-1,2-diol in edible oils. Food Addit. Contam. 23, 1290-1298(2006).

5) Weißhaar, R. Determination of total 3-chloropropane-1,2-diol (3-MCPD) in edible oils by cleavage of MCPD esters with sodium methoxide. Eur. J. Lipid Sci. Technol. 110, 183-186(2008).

6) Weißhaar, R. ILSI Europe Workshop (2009). http:// www.ilsi.org/Europe/Documents/E2009MCPD-7.pdf.

7) Weißhaar, R. Fatty acid esters of glycidol in refined fats and oils. Eur. J. Lipid Sci. Technol. 112, 158-165 (2010).

8) Masukawa, Y.; Shiro, H.; Nakamura, S.; Kondo, N.; Ooi, N.; Kudo, N. A new analytical method for the quantification of glycidol fatty acid esters in edible oils. $J$. Oleo Sci. 59, 81-83(2010).

9) The Japanese Food Safety Commission (2015) . http:// www.fsc.go.jp/sonota/dag/dag_index.html.

10) Ministry of Agriculture, Forestry and Fisheries of Japan. http://www.maff.go.jp/j/press/syouan/seisaku/ pdf/141217-02.pdf.

11) MacMahon, S.; Begleya, T. H.; Diachenko, G. W. Occurrence of 3-MCPD and glycidyl esters in edible oils in the United States. Food Addit. Contam. A 30, 2081$2092(2013)$.

12) Crews, C.; Chiodini, A.; Granvogl, M.; Hamlet, C.; Hrnčiř́k, K.; Kuhlmann, J.; Lampen, A.; Scholz, G.; Weißhaar, R.; Wenzl, T.; Jasti, P. R.; Seefelder, W. Analytical approaches for MCPD esters and glycidyl esters in food and biological samples: a review and future perspectives. Food Addit. Contam. A 30, 11-45 (2012).

13) JOCS Standard Method for the Analysis of Fats, Oils and Related Materials (Japan Oil Chem. Soc. ed.), 2.4.13-2013(2013).

14) Joint AOCS/JOCS Official Method(Am. Oil Chem. Soc. ed.), Cd 28-10 (2013).

15) Yamazaki, K.; Ogiso, M.; Isagawa, S.; Urushiyama, T.; Ukena, T.; Kibune, N. A new, direct analytical method using LC-MS/MS for fatty acid esters of 3-chloro-1,2- 
propanediol (3-MCPD esters) in edible oils. Food Addit. Contam. A 30, 52-68(2013).

16) Hori, K.; Koriyama, N.; Omori, H.; Kuriyama, M.; Arishima, T.; Tsumura, K. Simultaneous determination of 3-MCPD fatty acid esters and glycidol fatty acid esters in edible oils using liquid chromatography time-offlight mass spectrometry. LWT Food Sci. Technol. 48, 204-208 (2012).

17) Hori, K.; Matsubara, A.; Uchikata, T.; Tsumura, K.; Fukusaki, E.; Bamb T. High-throughput and sensitive analysis of 3-monochloropropane-1,2-diol fatty acid esters in edible oils by supercritical fluid chromatography/tandem mass spectrometry. J. Chrom. A. 1250, 99-104 (2012).

18) AOCS Official Method(Am. Oil Chem. Soc. ed.), Cd 29a (2013).

19) AOCS Official Method(Am. Oil Chem. Soc. ed.), Cd $29 \mathrm{~b}(2013)$.

20) AOCS Official Method (Am. Oil Chem. Soc. ed.), Cd 29c (2013).

21) Miyazaki, K.; Koyama, K.; Sasako, H.; Hirao, T. Indirect Method for Simultaneous Determinations of 3-Chlo-
ro-1,2-Propanediol Fatty Acid Esters and Glycidyl Fatty Acid Esters. J. Am. Oil Chem. Soc. 89, 1403-1407 (2012).

22) Koyama, K.; Miyazaki, K.; Abe, K.; Ikuta, K.; Egawa, Y.; Kitta, T.; Kido, H.; Sano, T.; Takahashi, Y.; Nezu, T.; Nohara, H.; Miyashita, T.; Yada, H.; Yamazaki, K.; Watanabe, Y. Optimization of an Indirect Enzymatic Method for the Simultaneous Analysis of 3-MCPD, 2-MCPD, and Glycidyl Esters in Edible Oils. J. Oleo Sci. 64, 1057-1064 (2015).

23) Collison, M. W. Current status of MCPD and Glycidol Analysis in Oils. in 104th AOCS Annual Meeting, Montreal, Canada, Presentation (2013).

24) AOAC Int., Appendix D. Guidelines for Collaborative Study Procedures to Validate Characteristics of a Method of Analysis. in Official Methods of Analysis of AOAC Int. 18 ed. Gaithersburg, USA (2005).

25) Thompson, M. Recent trends in inter-laboratory precision at ppb and sub-ppb concentrations in relation to fitness for purpose criteria in proficiency testing. Analyst 125, 385-386 (2000). 